\title{
Gender equality in university education in Egypt [Arabic]
}

Nagwa Megahed

Follow this and additional works at: https://knowledgecommons.popcouncil.org/departments_sbsr-pgy

Part of the Demography, Population, and Ecology Commons, Educational Sociology Commons, Family, Life Course, and Society Commons, and the Inequality and Stratification Commons How does access to this work benefit you? Let us know!

\section{Recommended Citation}

Megahed, Nagwa. 2015. "Gender equality in university education in Egypt [in Arabic]," Policy brief. Cairo: Population Council. 
العدالة والمساواة بين الجنسين في

(1)

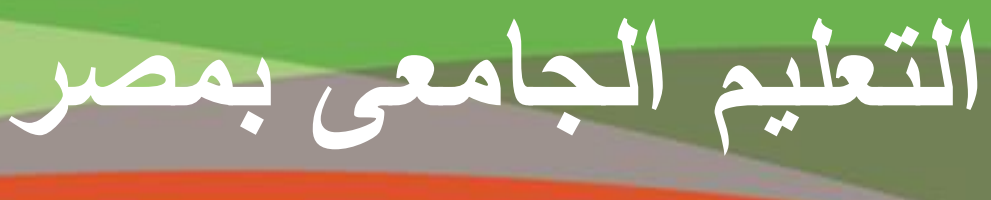

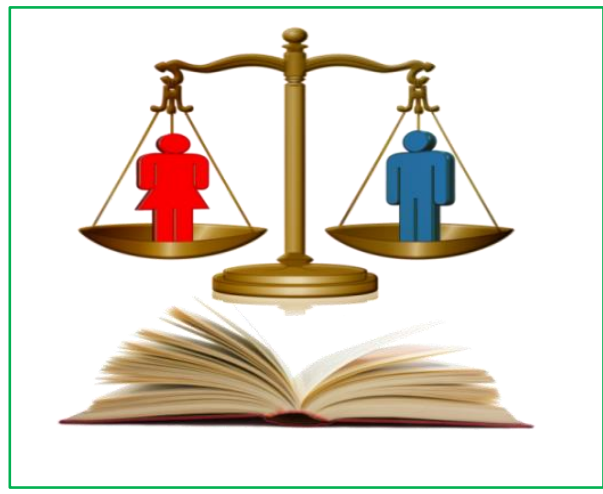

المساو اة و العدالة بين الجنسين تتضـمن السياسـات المرتبطـة

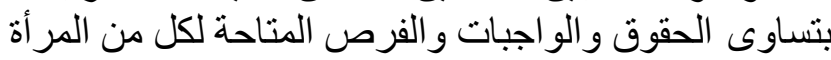

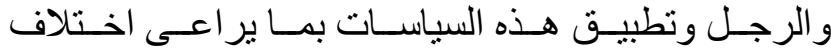

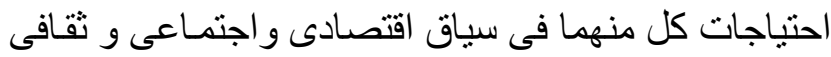

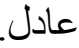

\section{الوضع الراهن للمرأة في التعليم الجامعي في مصر من الزمر}

تمثل مرحلة التعليم الجامعي قمة السلم التعليمي حيث تقبل الطلاب من الذكور والإناث ممن أنهوا المرحلة الثنانية النيانية

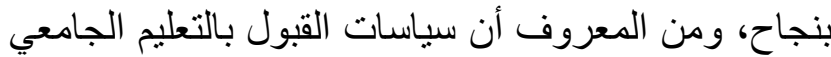

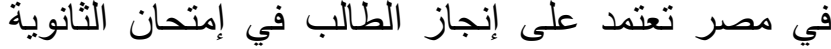
العامة الذي تعقده وزارة التربية والتعليم كإمتحان موحد

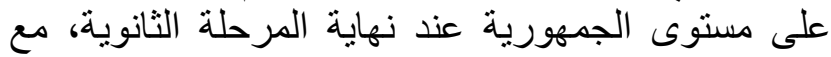

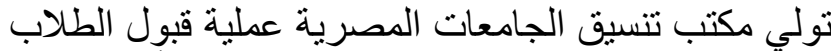

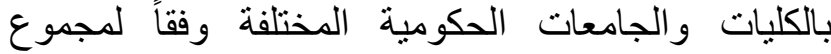
الدرجات التي حصل عليها الطالب في إمتحان الثانوية

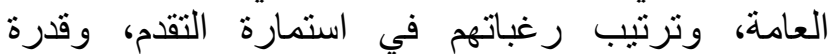

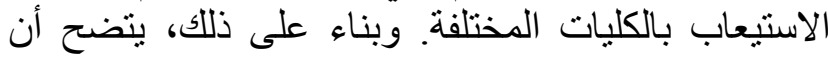
تحقيق المساواة والعدالة بين الجنسين في الالتحاق بالتعالئي

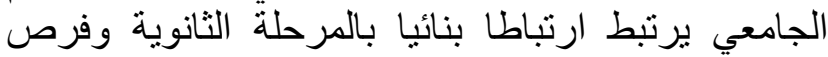

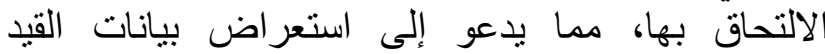

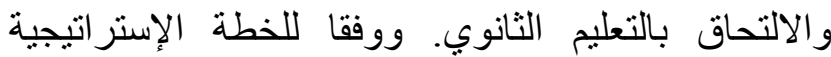

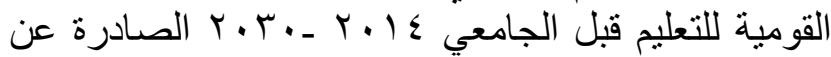

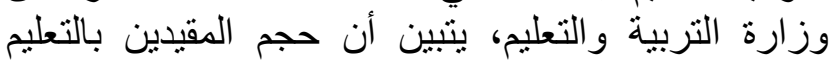

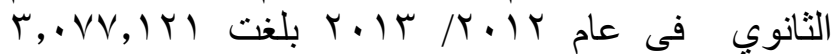

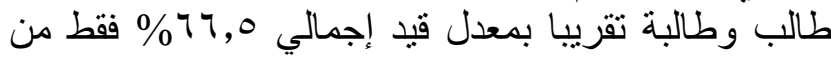

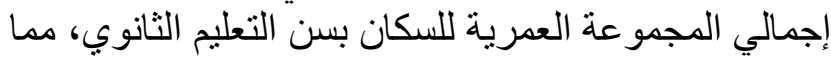

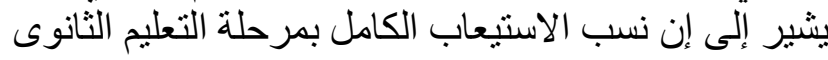

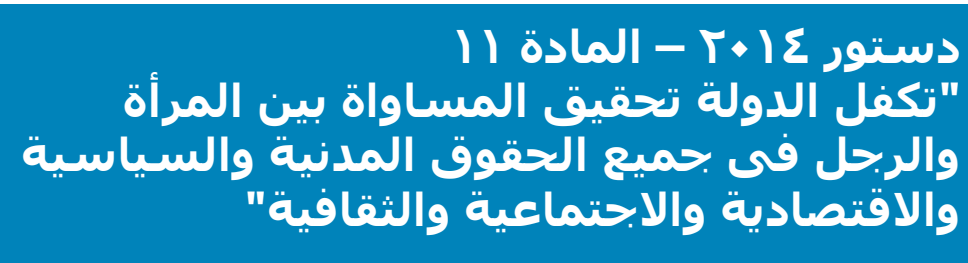

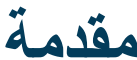

يعد تحقيـق العدالـة و المسـاو اة بين الجنسـين في التعليم هدفاً قوميـاً

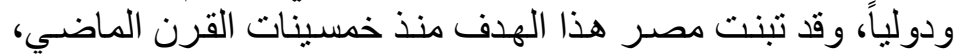

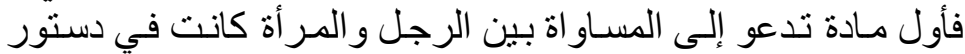

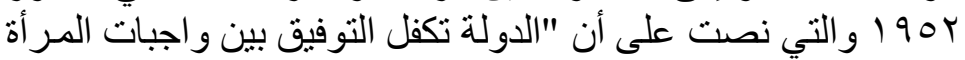

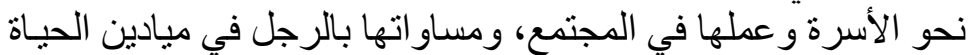

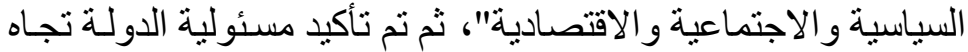

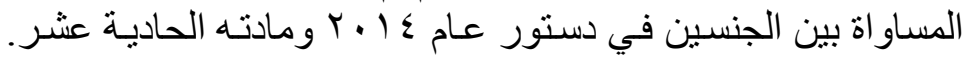

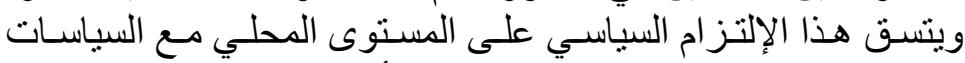

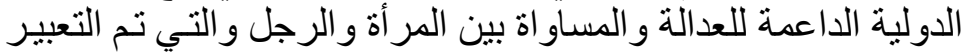

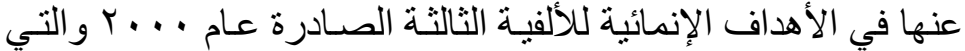

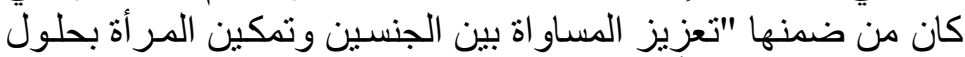

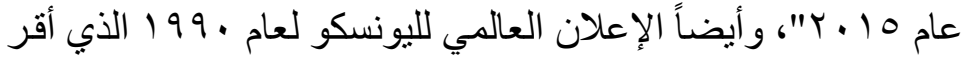

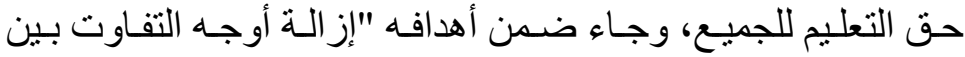

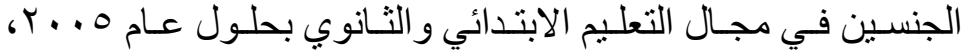

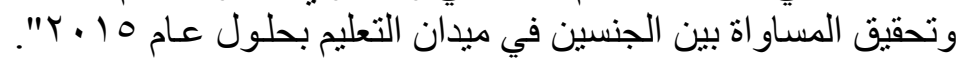

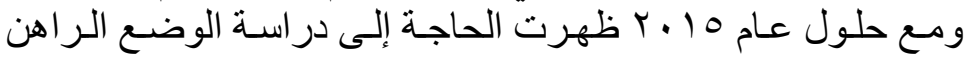

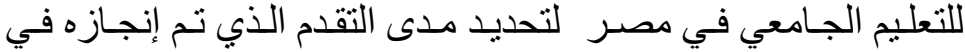

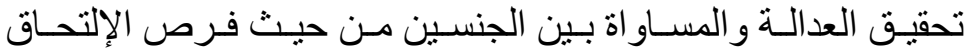

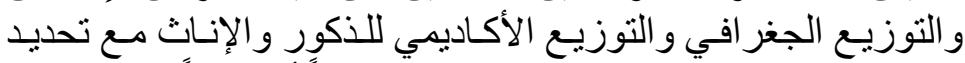

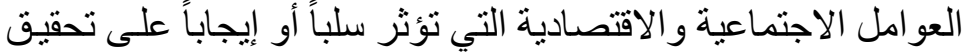

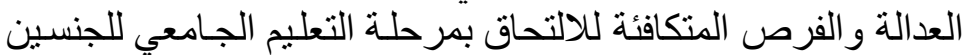
و التي ترتبط بدور ها بمر احل التعليم السـابقة وبخاصـة التعليم الثنانوى التئي وكذللك فرص العمل الناحقة.

وجدير بالذكر أن هنـاك فرق طفيف بين تعريف المسـاو اة وتعريف

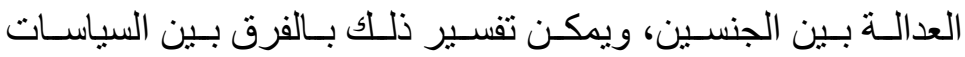

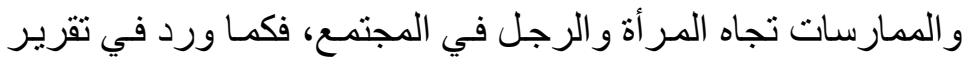

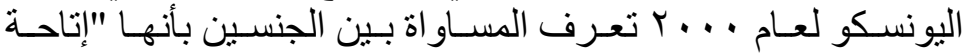

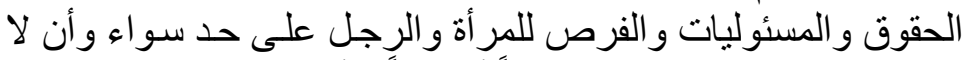

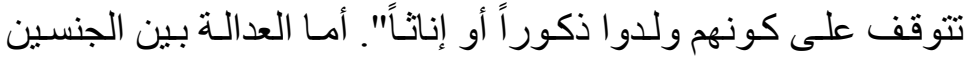

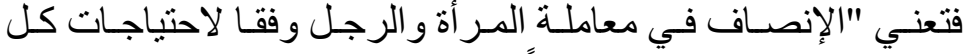

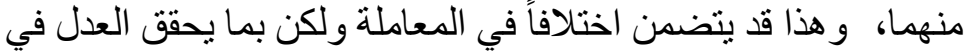

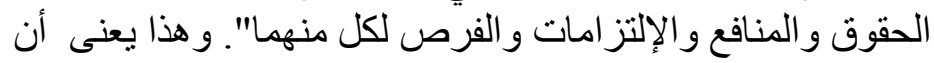

\section{POPULATION} COUNCIL

Ideas. Evidence. Impact. 
جدول (1) نسب الملتحقين بالتعليم العالي في مصر مقارنة

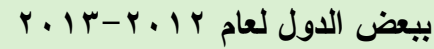

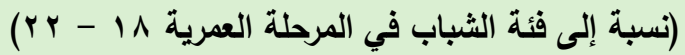

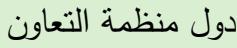

الاقتصادي والتتمية

مصر الدول العربية

\% $>1$

$\%$ Y०,०

$\% \curlyvee \wedge$

\section{World Bank DataBank 2012,}

Strategic Planning Unit 2014

التعاون الاقتصادي والتتمية فإن متوسط نسبة إلتحاق الإناث

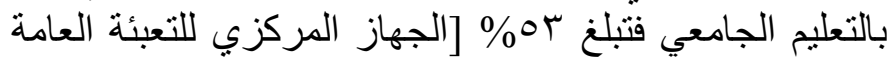

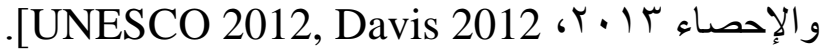

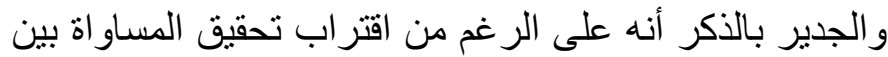
الجنسين من حيث النسبة الإجمالية للإناث الملتحقات بالتين التعليم

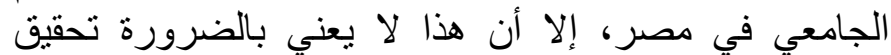
العدالة بين الجنسين وخاصة في عندما يتم تحليل نسب الإنب إلتحاق

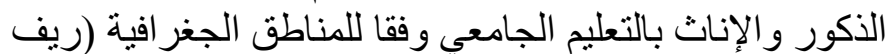

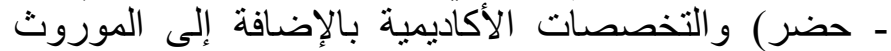
النقافي عن الدور المتوقع للمر أة في المجتمع.

\section{القجوة بين الجنسين من حيث المناطق

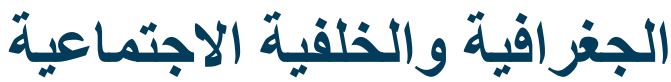

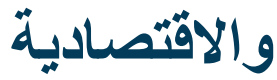

يحظى التعليم الجامعي في مصر كغير ها من الدول بنظرة إنواة

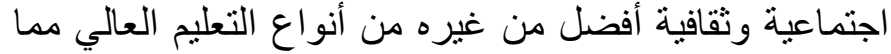

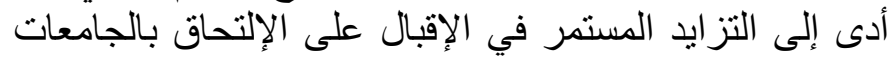

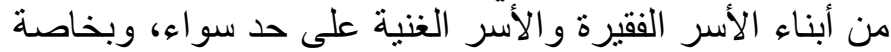

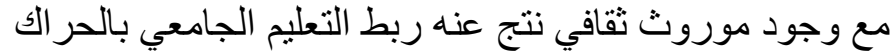

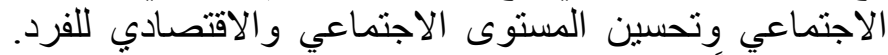

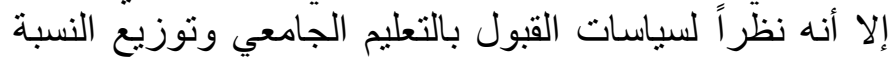

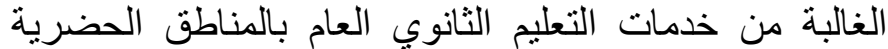

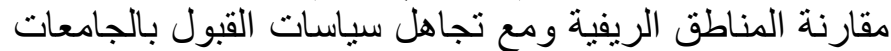
للخلفية الاجتماعية والاقتصادية للطلاب، من حيث الرية دخل الأسرة

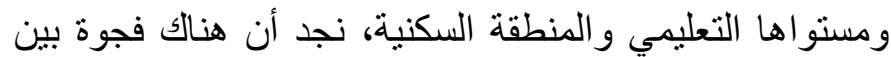
نسب إلتحاق الذكور بالتعليم الجامعي مقابل الإناث بالمناطقة

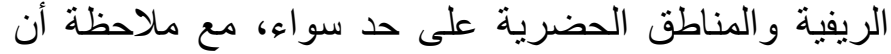

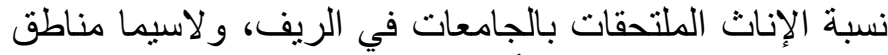
ريف الوجه القبلى، تزال أقل من معدلات التحات التحاق الذكور التهات كما

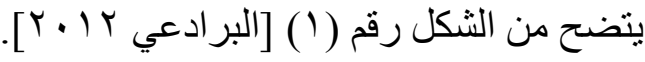

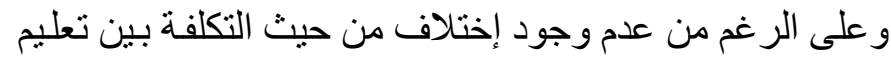

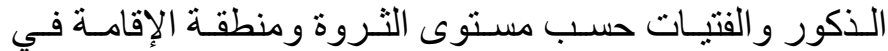

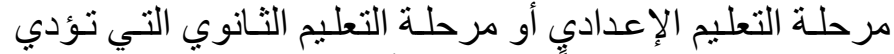

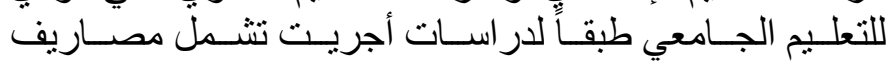
الدروس الخصوصية والإنتقال والرسوم الرسمية .... إلخ الخ التحلية

\section{POPULATION}

\section{COUNCIL}

Ideas. Evidence. Impact.

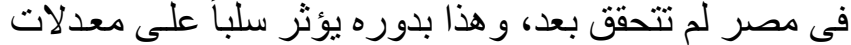

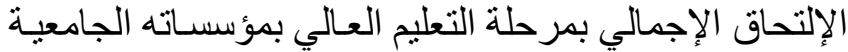

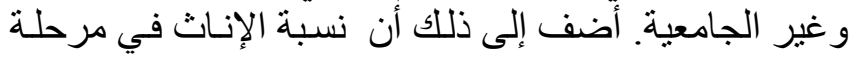

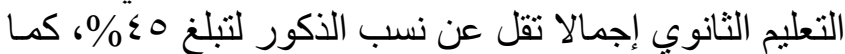

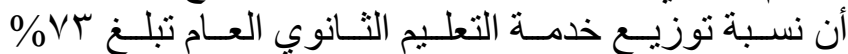

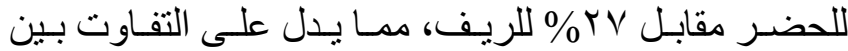

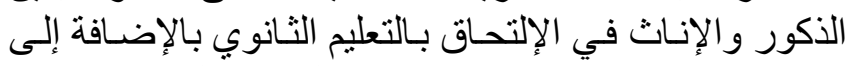

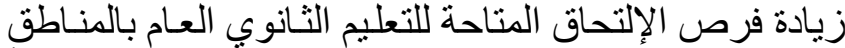

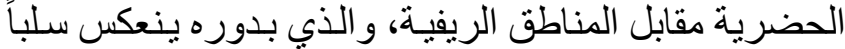

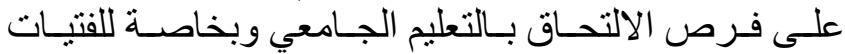

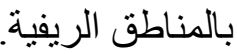

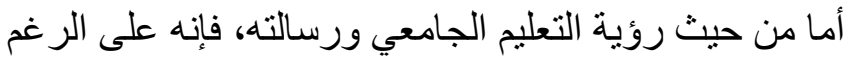

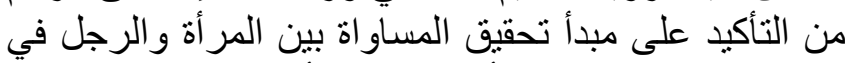

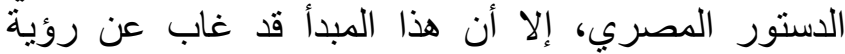

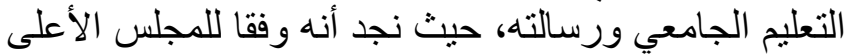

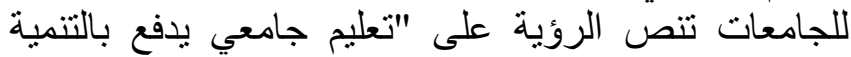

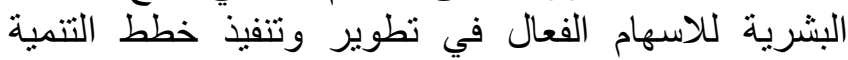
الاقتصادية للدولة وتطبيق التكنولوجيا الحديثة"، أما الرسالة

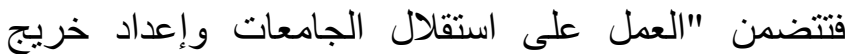

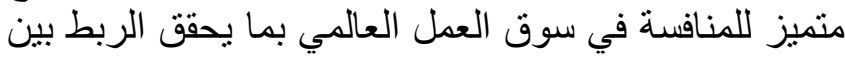

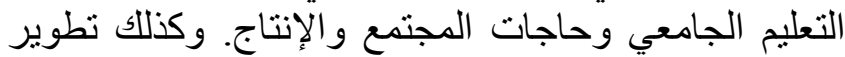
وتحديث آداء الجامعات من خلال تطبيق أساليب تقييم الآداء وضمان الجودة. تحقيق مجتمع المعرفة وتتجيع الإنيع الابتكار والإبداع في إطار المنافسة العلمية القائمة على العئ التميز

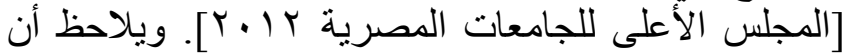
رؤية التعليم الجامعي ورسالته تتبلور حول التنمية البشرية

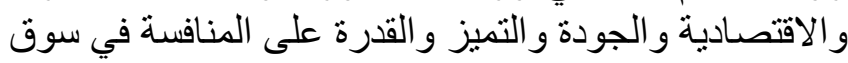

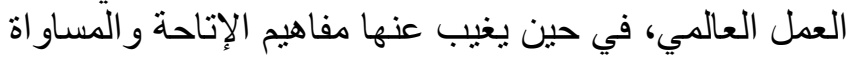
بين الجنسين و الحر اك الاجتماعي و العدالة الاجتماعية.

وفـي اطــار سياسـات القبـول بــالتعليم الجـامعي و الرؤيــة

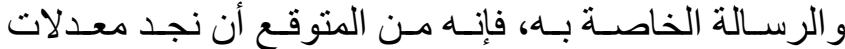

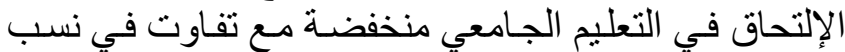

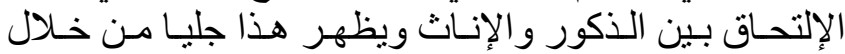

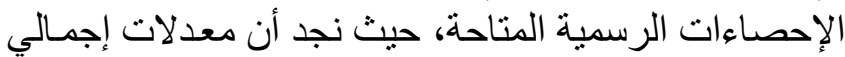

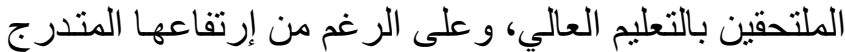

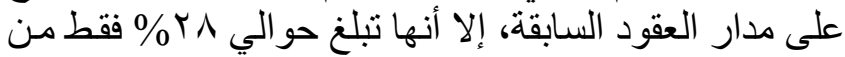

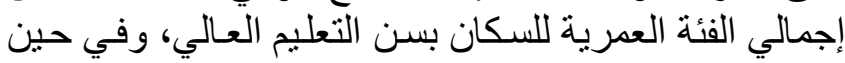

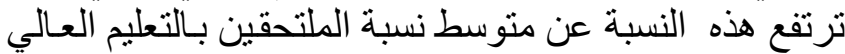

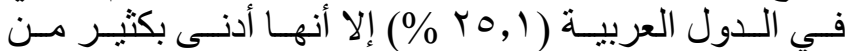

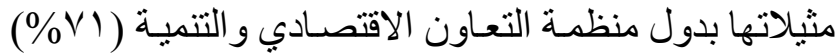

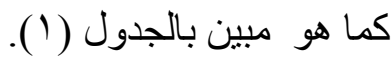

ومن حيث مشاركة الإناث في التعليم الجامعي في مصر فقد

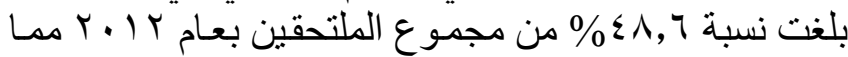
يشير إلى إقتر اب تحقيق المساو اة بين الجنسين، و هذه النسبة

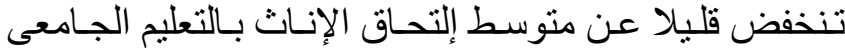

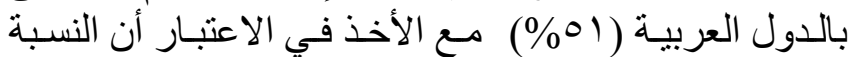

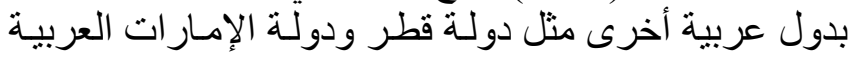

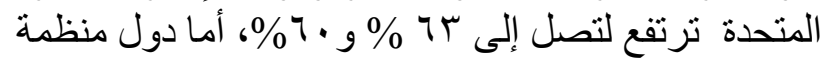




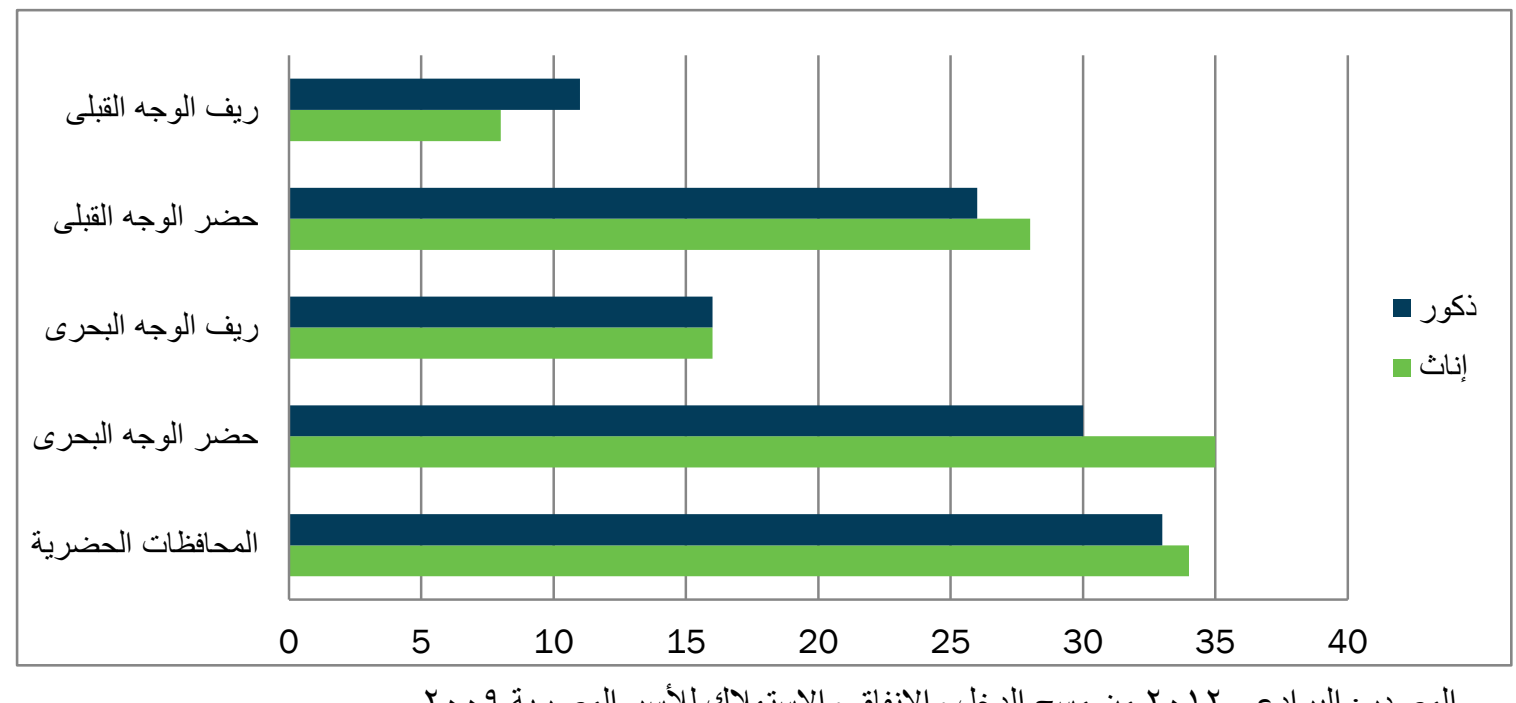

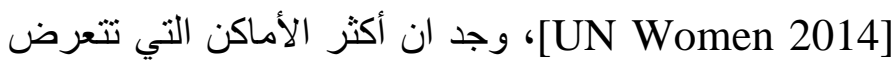

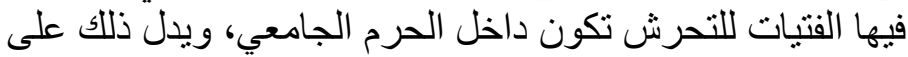

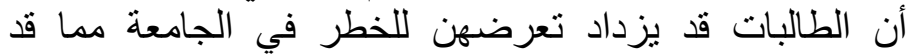

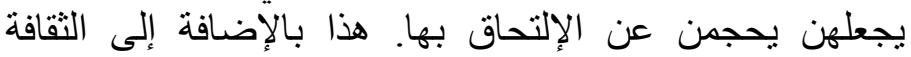
المحافظة لاى بعض الأسر وخاصة في المناطق الريفية و التي قد

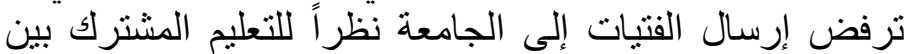

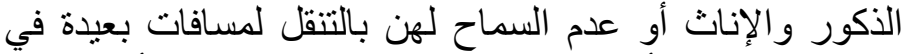

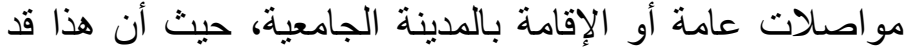

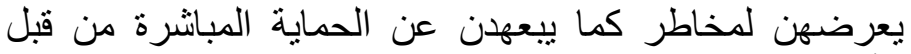

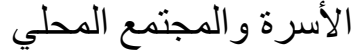

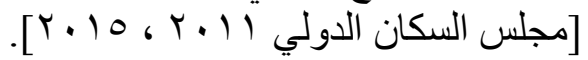
أضف إلى ذلك ما يعرف "بتكلفة الفرصة الضائعة" للطالبات

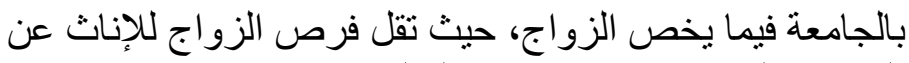

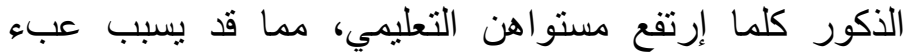

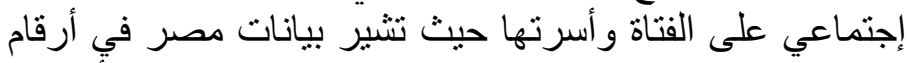

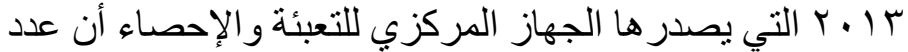

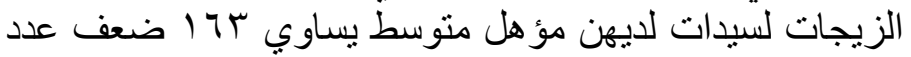

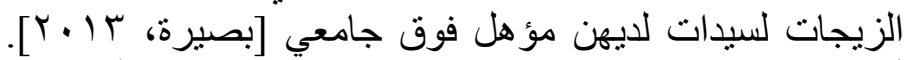

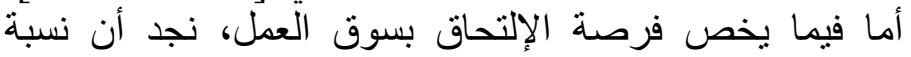

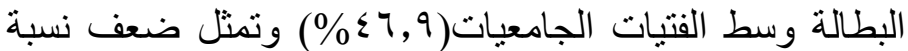

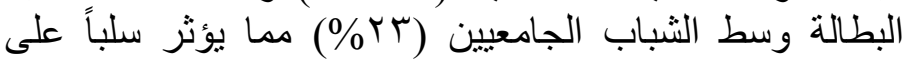

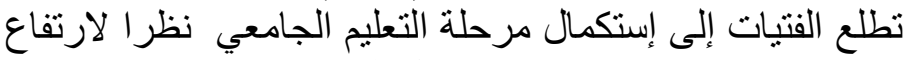

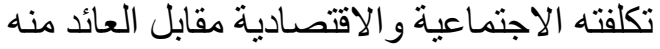

.[Barsoum et al. 2014]

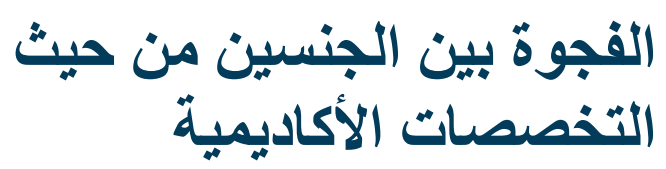

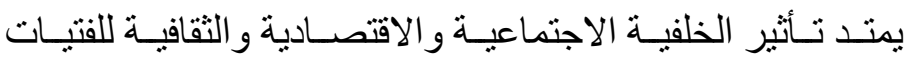

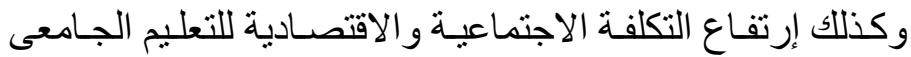

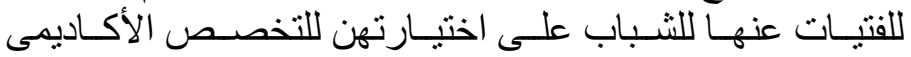
بالجامعة، فقد أظهرت بعض الدر اسات أن المستوى المادي

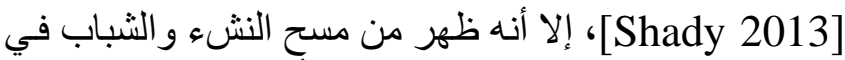

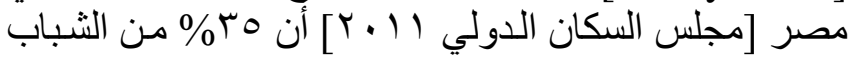

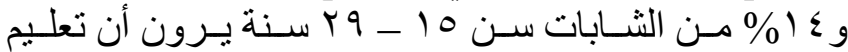

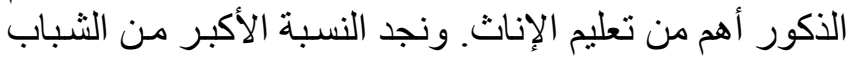

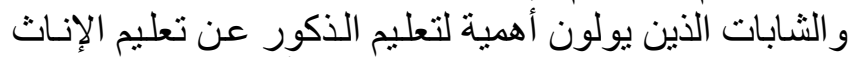

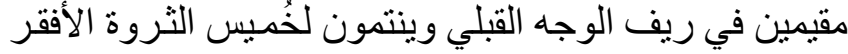

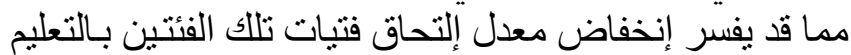

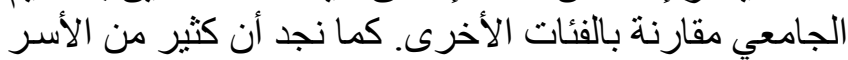

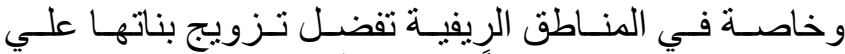

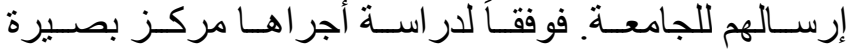

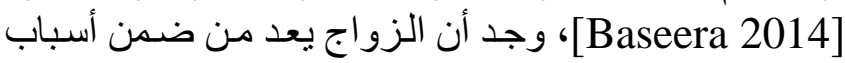

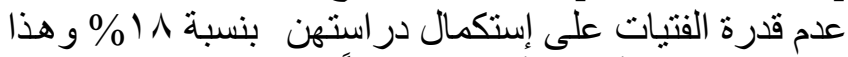
السبب يعد ثاني أكثر الأسباب شيو عاً بين الفتيات بعد تكاليف

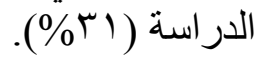

وبالإضافة إلى هذه الثقافة السائدة ببعض مناطق الوجة القبلي

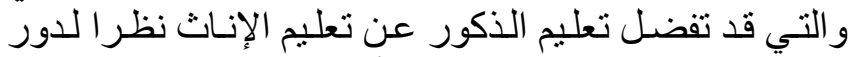

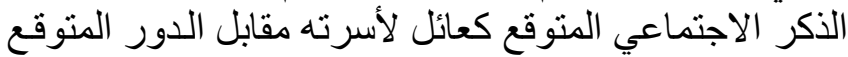

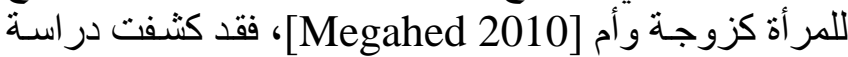

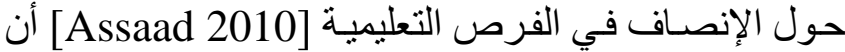

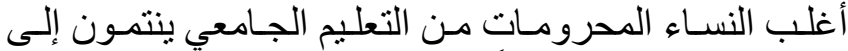

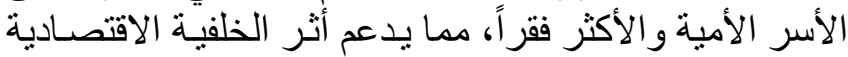

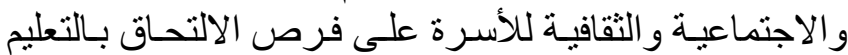

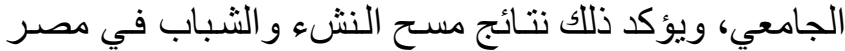

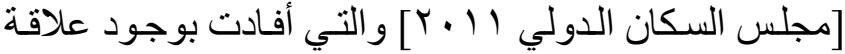

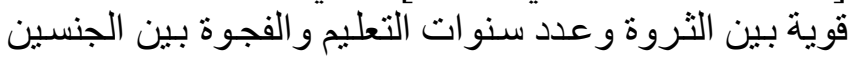

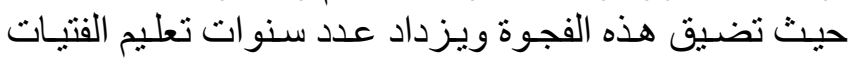

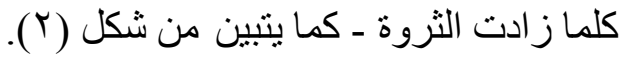
هذه الفجوة بين الجنسين ترتبط أيضا بالتكلفة الاجتماعية التي

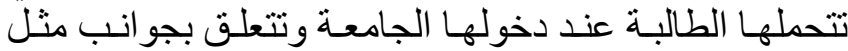

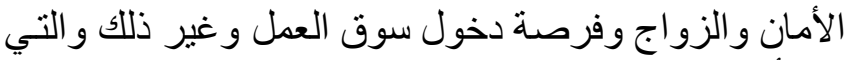

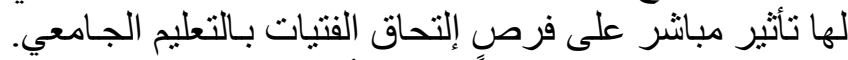

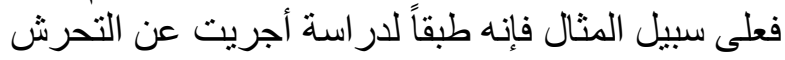

\section{POPULATION}




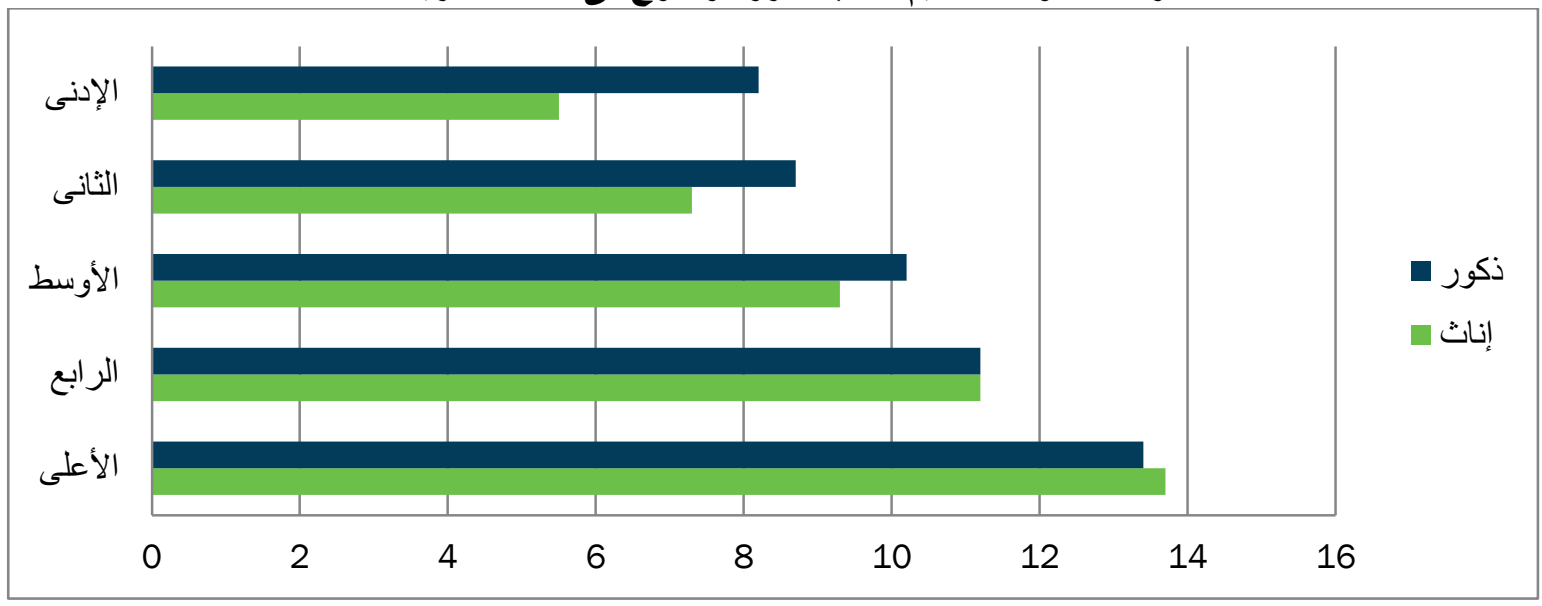

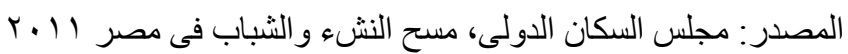

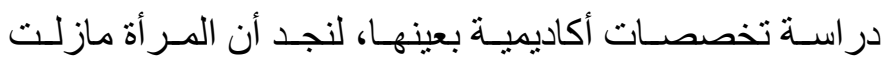

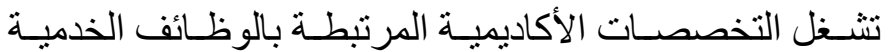

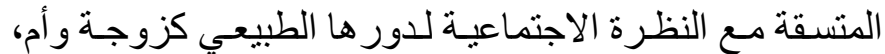

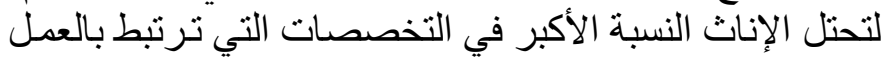

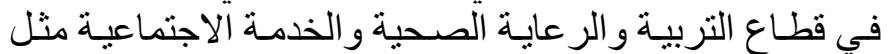
العلوم والآداب و التربية والطب، في حين التين يحتل الذكور النسبة

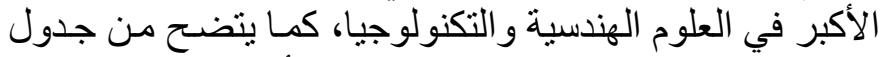

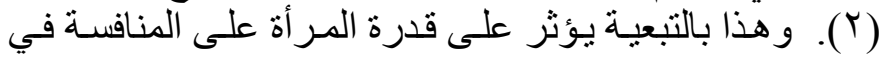
سوق العمل حيث تنخفض فرص العمل المتاحة ومقابلها المادي

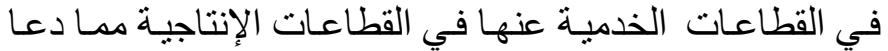

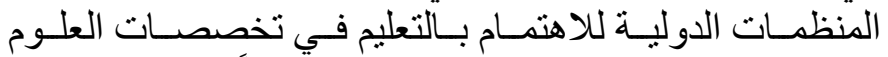

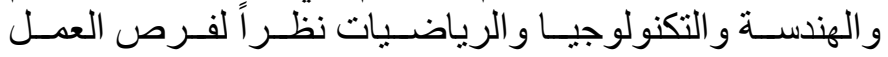

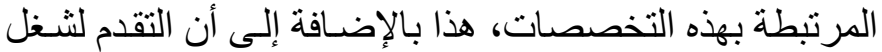

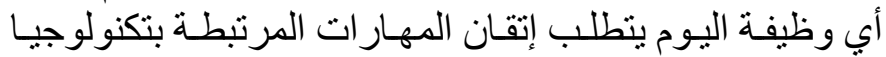

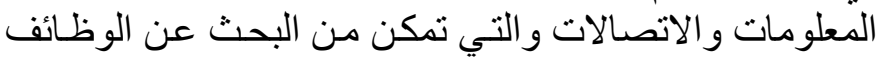
المتاحة والتقدم لها عبر الموالقع الإلكترونية

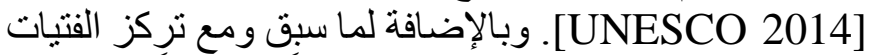

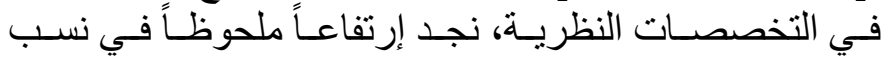

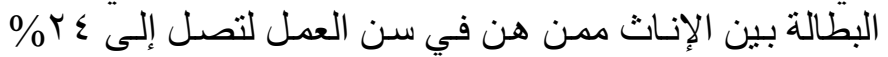

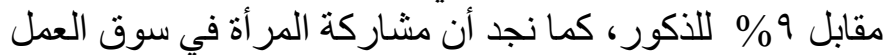

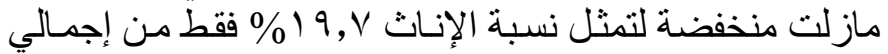

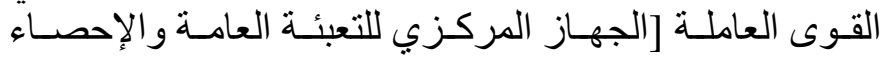

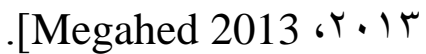

و على ضوء ما سبق، يتضح أن الفجوة بين الذكور والإناث

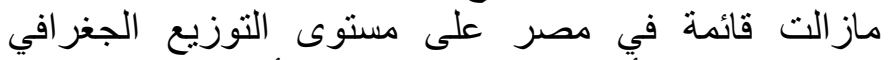

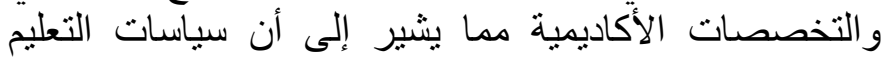
الجامعي وإن اقتربت من تحقيق المساواة بين الجنسين إجمالاً

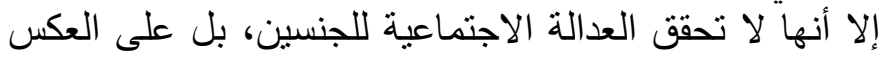

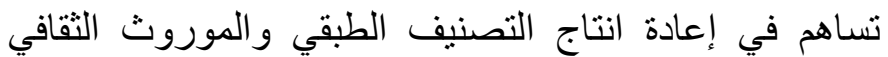

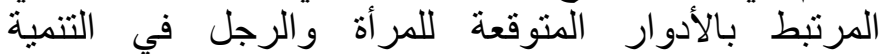
المتمعية، مما يؤثر سلبا على توفير الفرص الفئ المتكافئَة للمرأة في التعليم وسوق العمل وتحقيق العدالة الاجتماعية للجنسين.

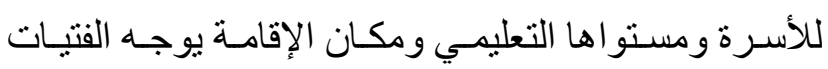

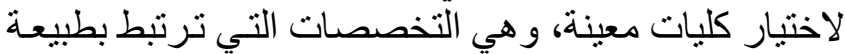

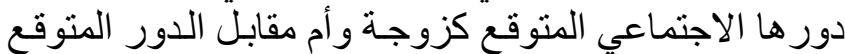

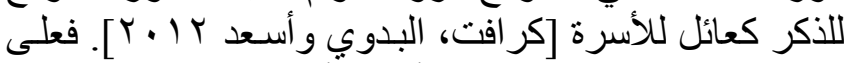
سبيل المثال نجد الفتيات من الأسر الأكثر ثر اء تلاء تلتحق بكليات

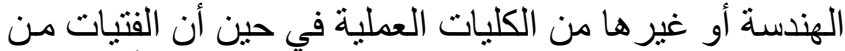

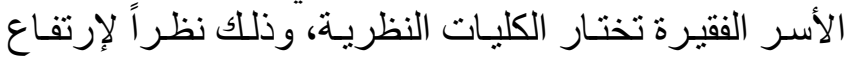

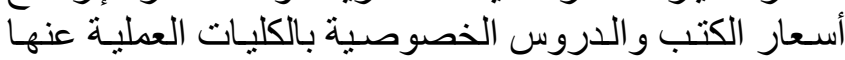

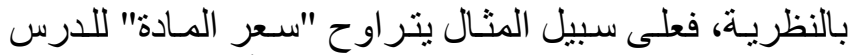
الخصوصي بالكليات النظريـة (كالاقتصـاد أو الإحصـاء بكلية النية

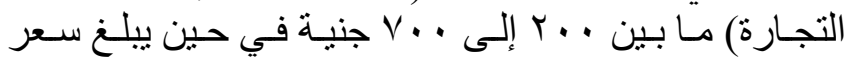

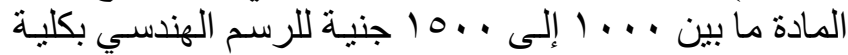

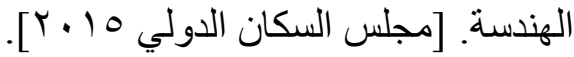

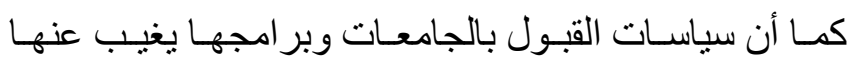

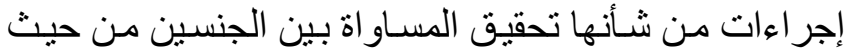

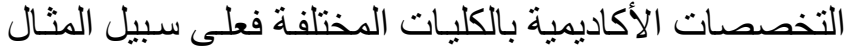

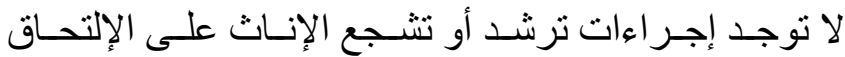
بتخصصات مثل الهندسة و التكنولو أونيا

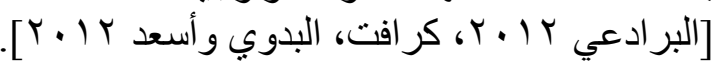

فعلى الرغم من تقديم ما يعرف بالآلداعم الجامعي داخل الكليات إلا أنه وفقاً للار اسة الكيفية حول التكلفة الفعلية التي لتي

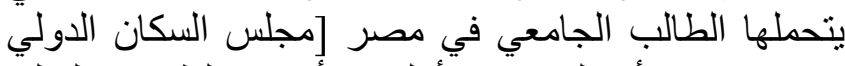

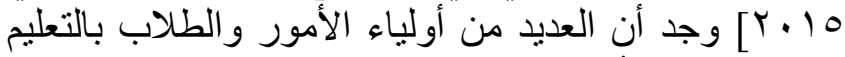

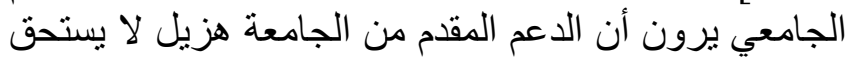

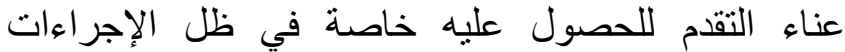

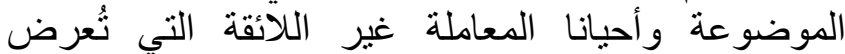

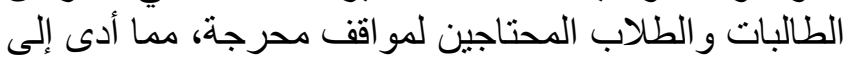

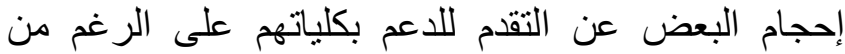

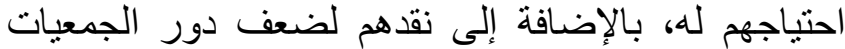
الأهلية في دعم التعليم الجامعى وبخاصة للفئية للفيات.

ويثير ما سبق إلى أن اختيار الفتيات لكليات وتخصصات

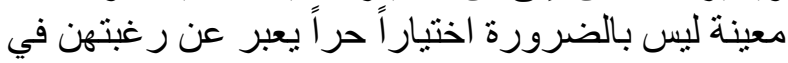




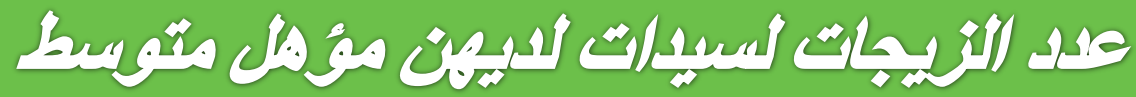

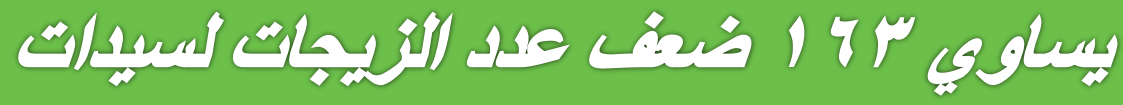

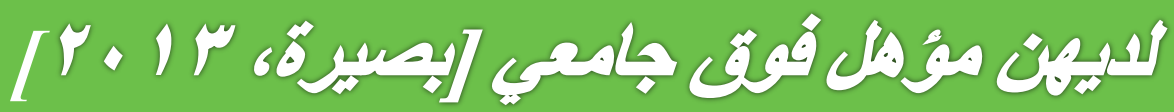

\section{القضاء على جذور الفجوة بين الجنسين في التعليم الجامعي}

إن تحقيـق العدالـة والإنصـاف في التعليم الجـامعي يجب أن يبـأ

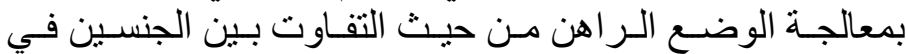

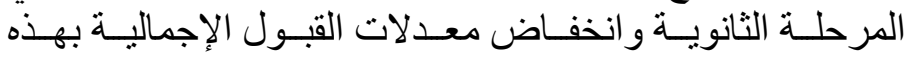

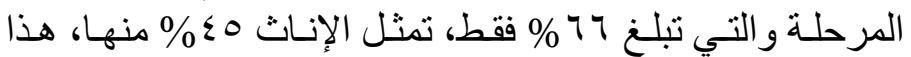

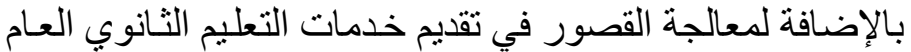

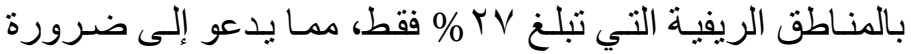

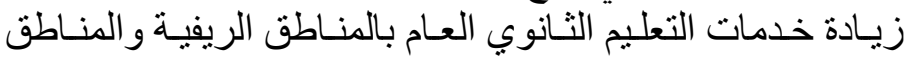

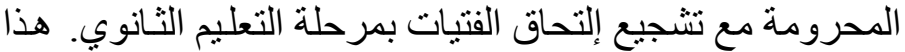

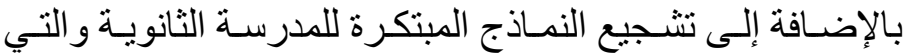

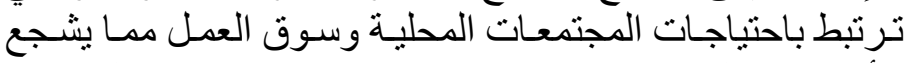

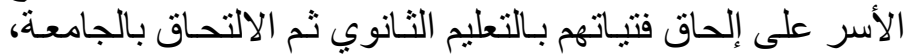

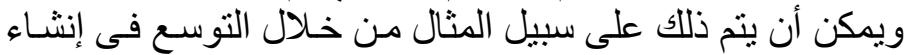

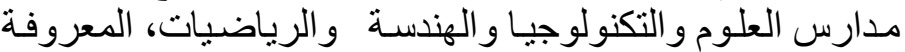
اختصار ا بـمدارس STEM نسبة إلى

Sciences, Technology, Engineering, and Mathematics و ألا يقتصر وجودهـا في مصـر على مدرسـة واحدة للفتيات تـم

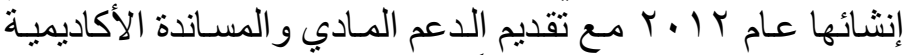

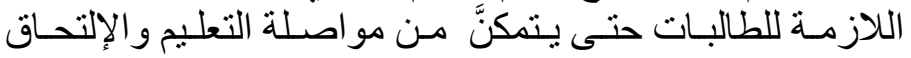

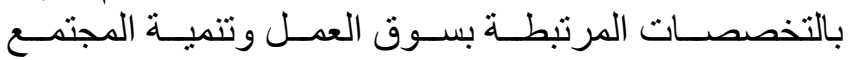

.[Rissmann-Joyce and El Nagdi 2013]

كما أن هناك حاجة إلى مر اجعة سياسات القبول بالتعليم العالي

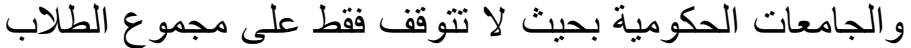

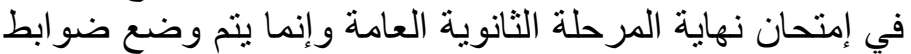

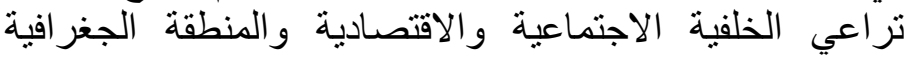

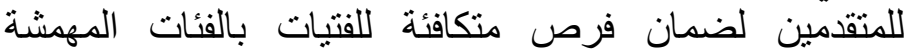

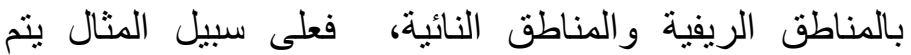
تخصيص نسبة إلتحاق بالتعليم الجامعي للفتيات من المناطق

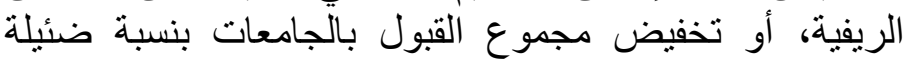

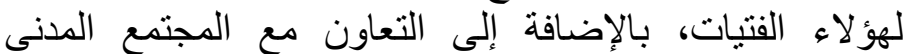

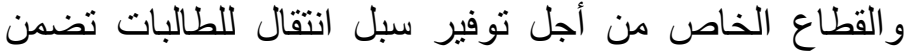

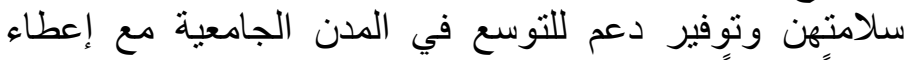
تمييزاً إيجابياً للفتيات في الإلتحاق بهذه المدن.

\begin{tabular}{|c|c|c|}
\hline \multicolumn{3}{|c|}{$r .1 r-r .11$} \\
\hline إناث (\%) & ذكور (\%) & التخص الأكاديمي \\
\hline $77, \varepsilon \pi$ & rT,OV & التزبية \\
\hline $09,1 T$ & $\varepsilon \cdot, \wedge \vee$ & العلوم الأساسية \\
\hline$\varepsilon 9,7 \wedge$ & $0 ., M r$ & الطب \\
\hline$r q, \cdot r$ & $V \cdot, 9 V$ & الهندسة \\
\hline$V \Gamma, \Sigma\rceil$ & rT,Or & الآداب والعلوم الإنسانية \\
\hline$\varepsilon r, \wedge r$ & 07,11 & الزراعة والطب البيطري \\
\hline$V \Gamma, \leqslant 0$ & $r 7,00$ & الخدمة الإجتماعبة \\
\hline$V 7, \sum 7$ & $r T, \leq 0$ & فنون جميلة \\
\hline 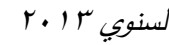 & ل والإحصاء، & لمصدر: الجهاز المركزي لا \\
\hline
\end{tabular}

مقترحات لسياسات وممارسات أكثر عدالة بين الجنسين في التطليم الجامعي

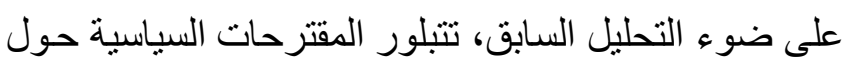

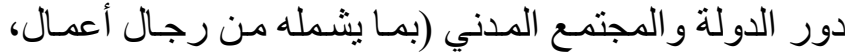

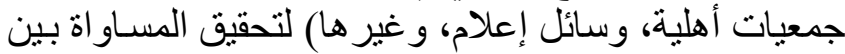

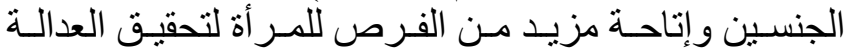

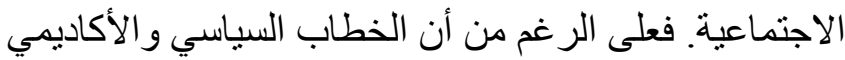

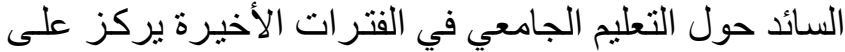

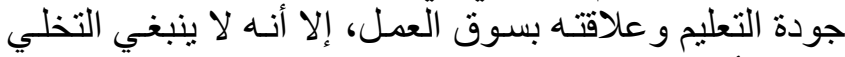

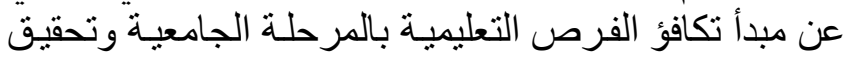

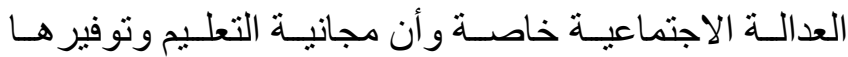
لمستحقيها هو حق كفله الدستور للمواطنين.

لهذا كان التوسـع في التعليم العـالي بعامـة و التعليم الجـامعي

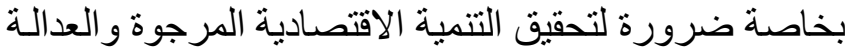

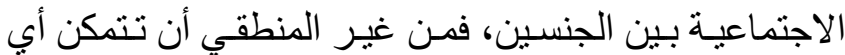

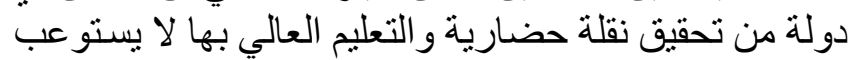

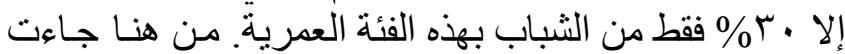

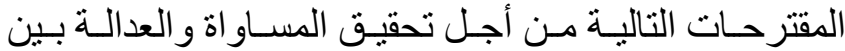
الجنسين في التعليم الجامعي. 
وكذلك التوسع في بر امج التعلم عن بعد، وتصميم بر امج التعلم

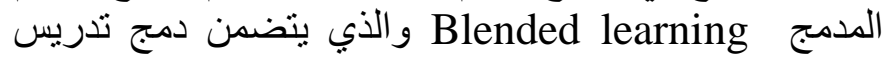

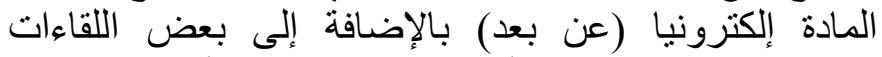

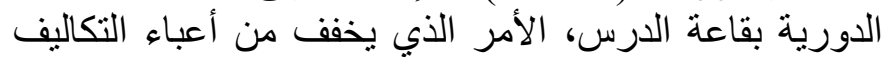

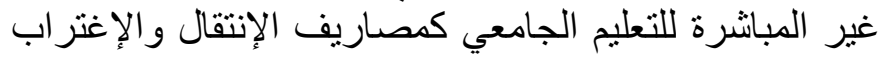

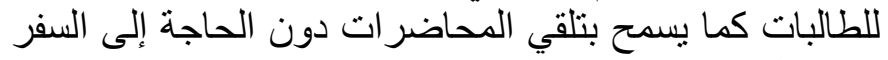

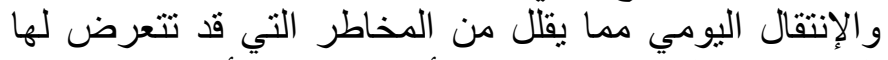

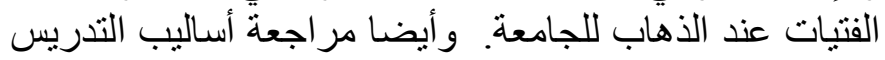

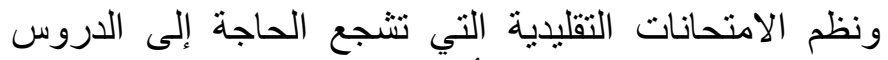

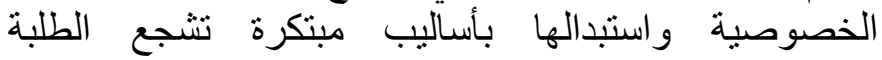
و الطالبات على البحث و الإطلاع و النقاش و المناظرة مما يشجع

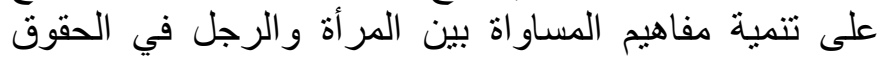

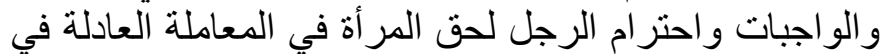
التعليم و المجتمع.

\section{قصة كماح}

سـارة طالبـة بالصـف الثالث بكليـة صـيدلة

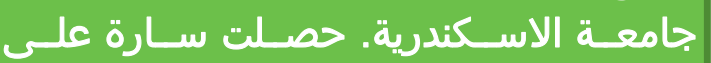

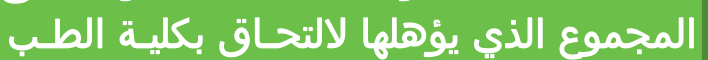

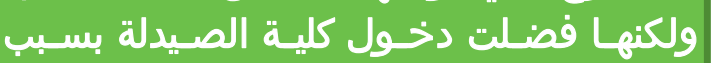

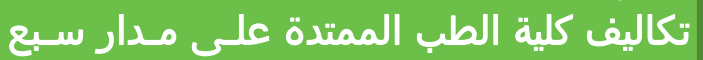

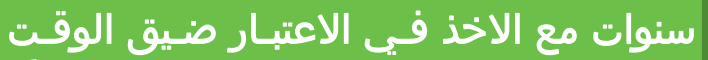

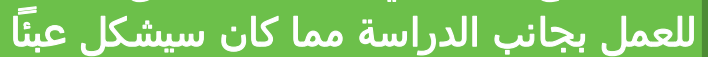

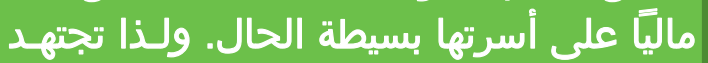

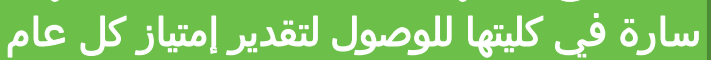

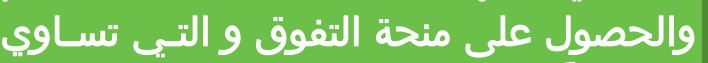

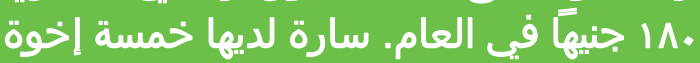

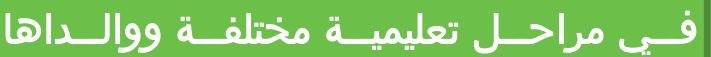

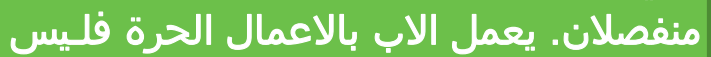

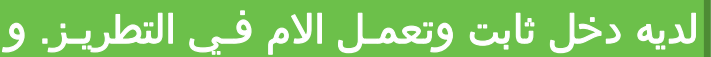

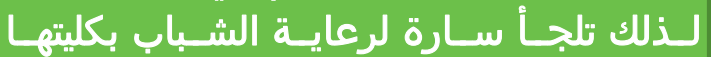

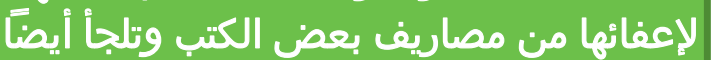

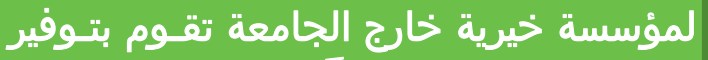

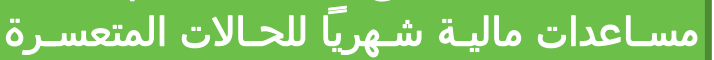

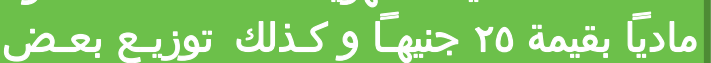

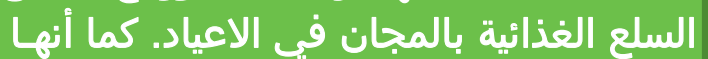

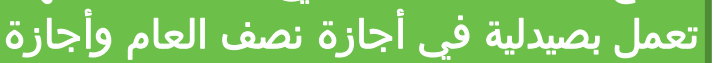
الصيف للتدريب ولمساعدة والدازية نصف الدفا في تغطية واجازية

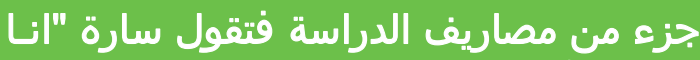
اتعودت أتحمل المسؤولية الدراسة فتى لو مش سارئ معايا

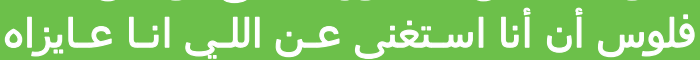

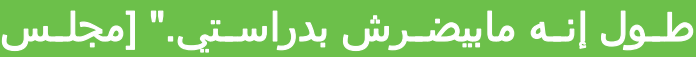

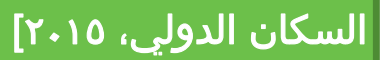

انشاء جامعات صغيزة وتحديث

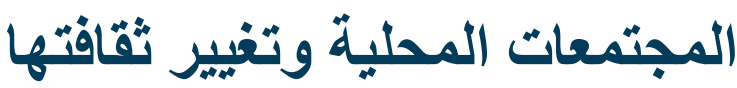

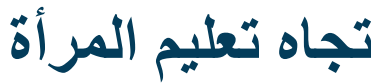

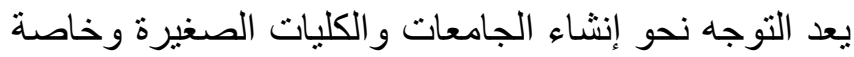

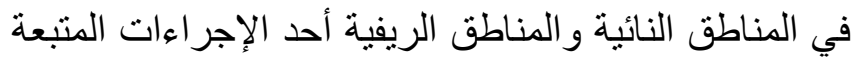
ببعض الدول [College Board 2014] حيث أنها تساهم الأني في تحديث المجتمع المحلي وخدمته مع تغيير ثقافته و إتاحة

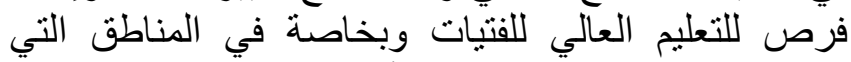
تسودها ثقافة محافظة تجاه المرأة، وهذا التوجة يمكن تبنيه

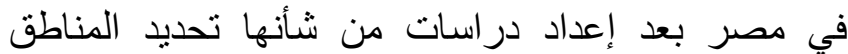

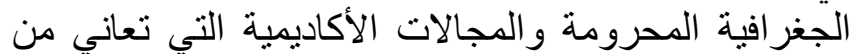

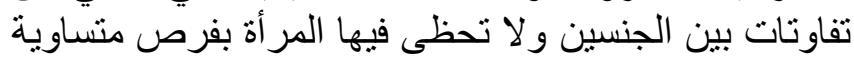
للتعليم الجامعي، مع تشجيع رجال التال الأعمال بهذه المناطق

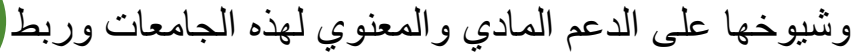

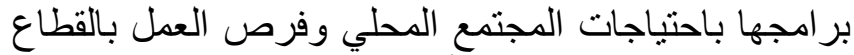

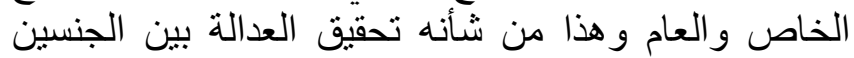

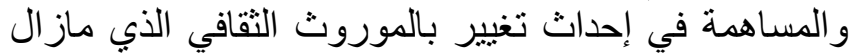
يعوق المرأة عن مواصلة تعليمها الجامعي نظر العزا لعدم توفره

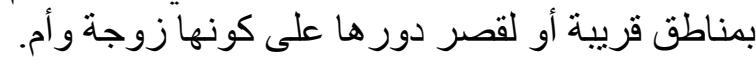

وبرتبط بهذا التوجة الحاجة إلى الاهتمام بربط القبول

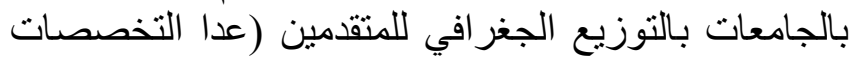

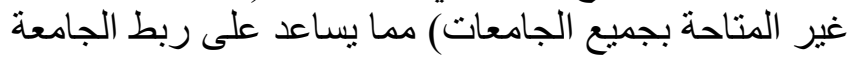
بالمحافظة التي تتنمي إليها ومراعاة الهاة احتياجاتها الاقتصادية

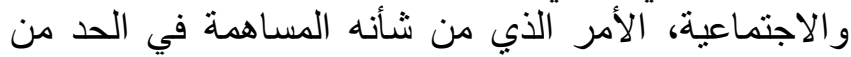

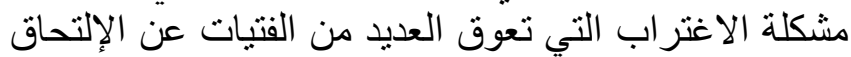

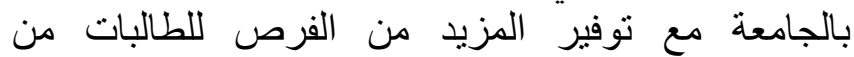
المحافظات النائية و المناطق الريفية.

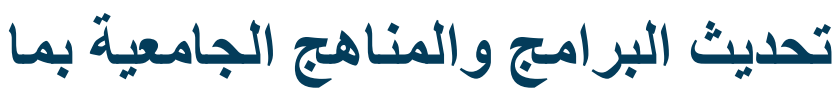 يحقى المساواة بين الجنسين}

هناك حاجة ماسة إلى تغيير الخطاب السائد الذي يقصر دور التهاب

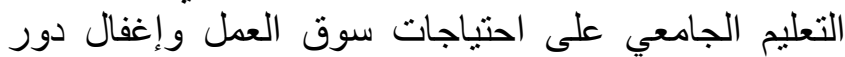
الجامعة في التربية الإنسانية الحضارية (بجانب المعارف

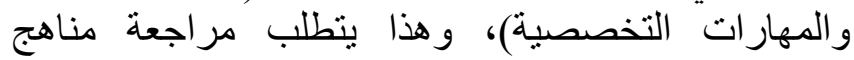

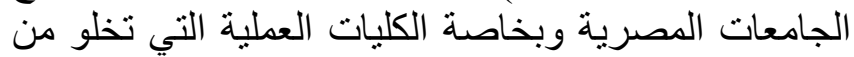
المقررات الإنسانية، ويضعف بهات الإنها المناظرات الأدبية والأنشطة الثقافية التي تنمي داخل الطلاب مفاهيم المواطنة الأنية

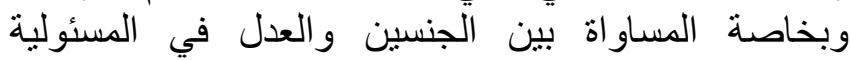

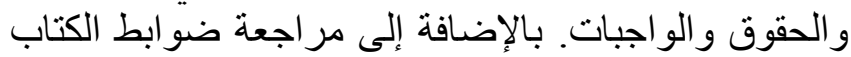

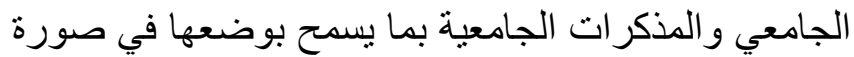

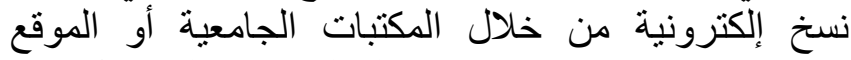

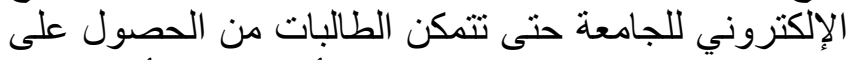

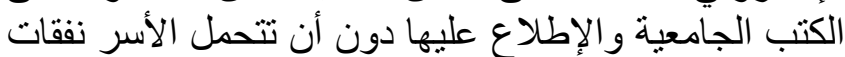

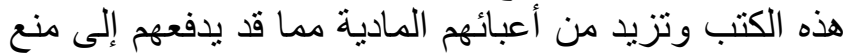
فتياتهم من استكمال در استنهم الجامعية.

\section{POPULATION}




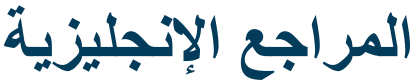

Assaad, Ragui (2010). Equality for all? Egypt's free public higher education policy breeds inequality of opportunity. Economic Research Forum.

Baseera (2014). Egyptian Women's Aspirations Post January $25^{\text {th }}$ Revolution.

Barsoum, Ghada, et al. (2014). Labour Market Transitions of Young Women and Men in Egypt.ILO.

http://www.ilo.org/wcmsp5/groups/public/---dgreports/--dcomm/documents/publication/wcms_247596.pdf

College Board (2014). Sizing up colleges: Big vs small. https://bigfuture.collegeboard.org/find-colleges/how-tofind-your-college-fit/sizing-up-colleges-big-vs-small

Davies, Catriona (2012) Mideast women beat men in education, lose out at work. CNN.

http://edition.cnn.com/2012/06/01/world/meast/middle-eastwomen-education/

Megahed, Nagwa \& Stephen Lack. (2013). Women's Rights and Gender-Educational Inequality in Egypt and Tunisia: From Colonialism to Contemporary Revolution. Pp. 201222 in D. Napier \& S. Majhanovich (Eds.) Education,

Dominance and Identity. Comparative and International Education: A Diversity of Voices, Volume 20. Rotterdam, the Netherlands: Sense Publishers.

Megahed, Nagwa (2010). Access to the University and Women's Participation in Higher Education in Egypt. The Middle East Institute. Web-based Volumes on Higher Education in the Middle East, Volume 2, Empowering Underserved and Vulnerable Populations.

http://www.mei.edu/LinkClick.aspx?fileticket=vBOcNODJ bGg\%3d\&tabid=541

Rissmann-Joyce, S. \& Mohamed El Nagdi. (2013). A case study- Egypt's first STEM schools: Lessons learned. Proceeding of the Global Summit on Education

Shady, Eman (2013). Gender, Tutoring and Track in Egyptian Education. Social Research Center. The American University in Cairo.

http://paa2013.princeton.edu/papers/130883

Strategic Planning Unit (2014).

UN Women (2014). Study on Ways and Methods to

Eliminate Sexual Harassment in Egypt.

http://harassmap.org/en/wp-

content/uploads/2014/02/287_Summaryreport_eng_low1.pdf

UNESCO (2000). Gender Equality and Equity. A Summary review of UNESCO's Accomplishments since the Fourth World Conference on women.Beijing.. UNESCO: Unit for the Promotion of the Status of Women and Gender Equality.

UNESCO (2012). Education Statistics. <

http://data.uis.unesco.org/>

UNESCO (2014). Commission on the status of women, fifty-eighth session, review theme: "Access and participation of women and girls in education, training and science and technology, including for the promotion of women's equal access to full employment and decent work,"18 March 2014, Issues Paper.

World Bank (2012). DataBank.

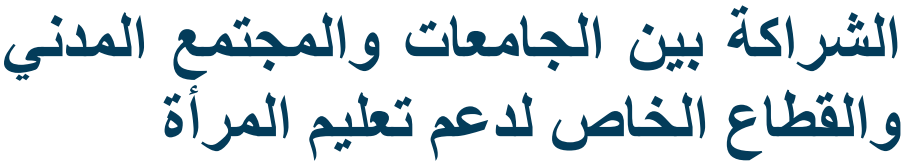

تشجيع مساهمة المجتمع المدني في دعم الطالبات من الفئات

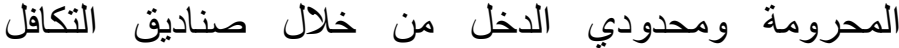

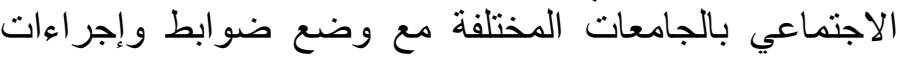

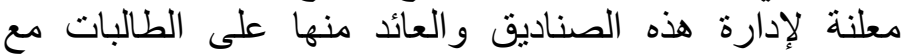

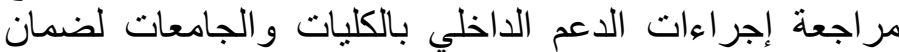
وصوله إلى مستحقيه دون التعرض لمرات لمضايقات أو إهانات.

الاستعانة بالقتوات التعليمية التلفزيونية وتحسين جودة برامجها بحيث تتنفع بها الطالبات من الفئات المهمشة ومحدودي الدخل، فئه وبخاصة في المواد التي تنتشر بها الدروس الخصوصبة العلمية

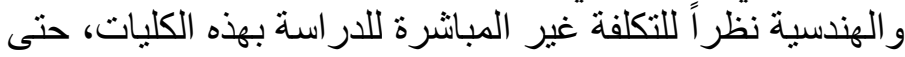

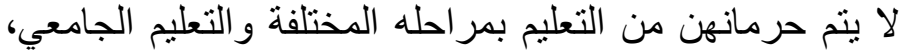

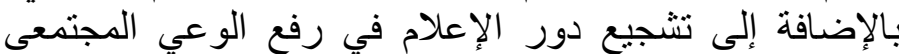

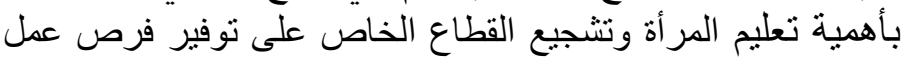
للمر أة تحترم آدميتها وتر اعي ظروفها العي الإجتماعية.

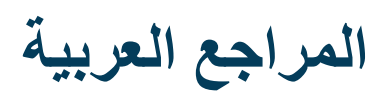

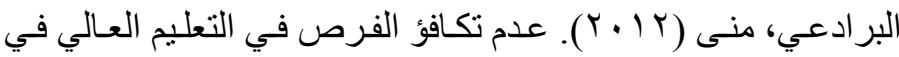

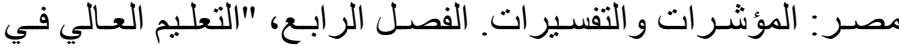

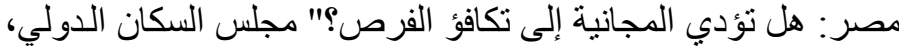

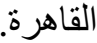

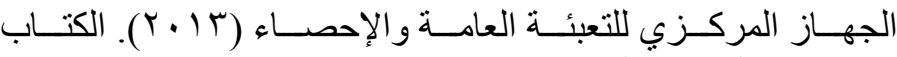

الإحصائي السنوي. القاهرة.

دستور جمهورية مصر العربية (ـ ا ـ ب). الهيئة العامـة للاستعلامات. $<$ http://www.sis.gov.eg/Newvr/consttt\%202014.pdf>

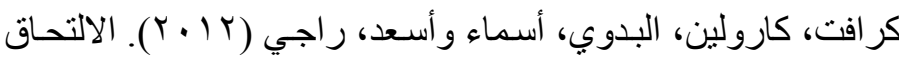

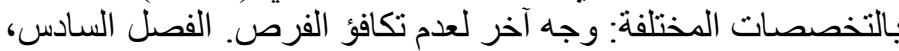

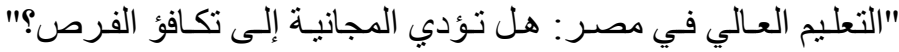
مجس السكان الدولي، القاهرة. المجلس الأعلى للجامعات المصرية (Y I • ب). $<$ http://www.scu.eun.eg/wps/portal $>$

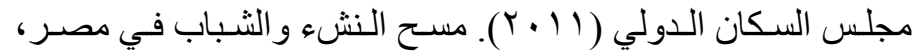
مجلس السكان الدولي. القاهرة.

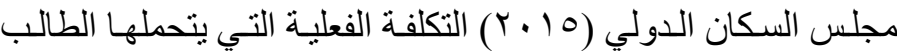
الجامعي في مصر. مجلس السكان الدولي ، القاهرة.

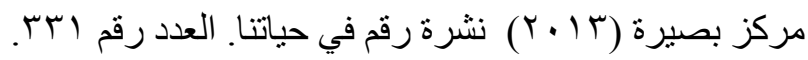
وزارة التربية و التعليم (ع ا ـ Y). الخطة الإستر اتيجية للتعليم قبل

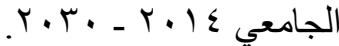
http://portal.moe.gov.eg/AboutMinistry/Pages/plan2014.aspx 


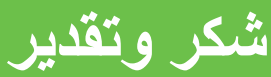

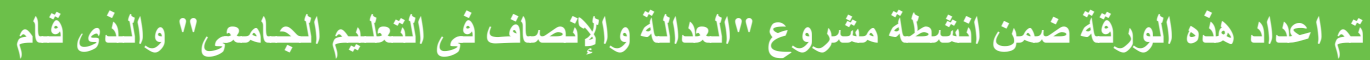

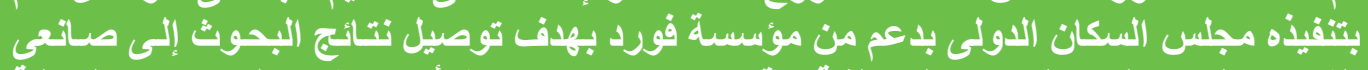

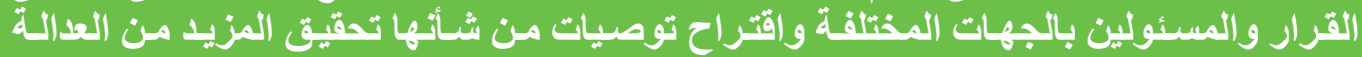

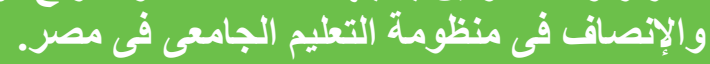

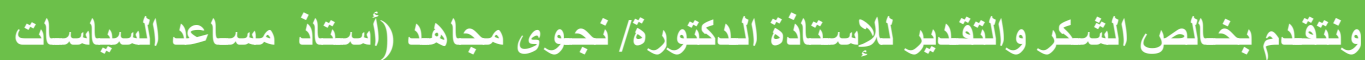

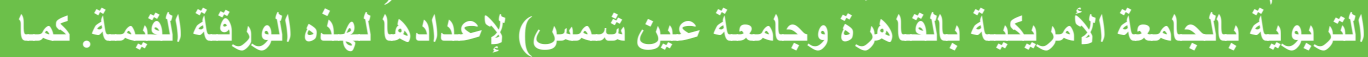

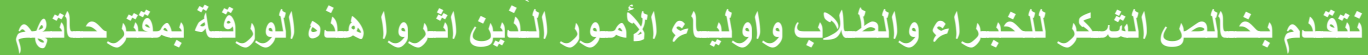

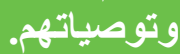

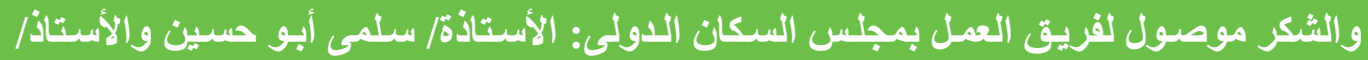

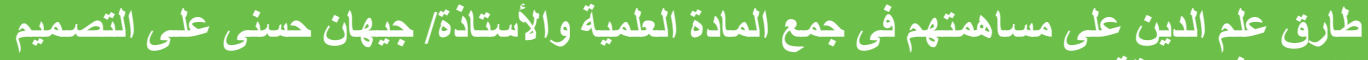

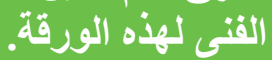

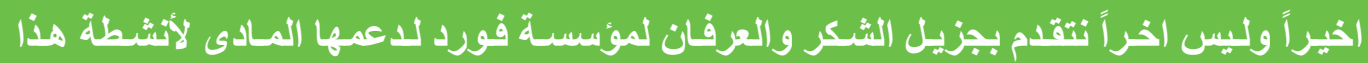

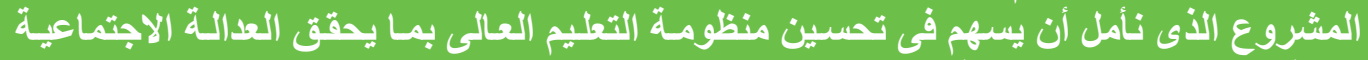

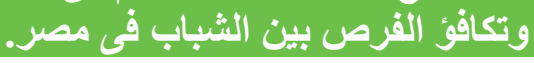

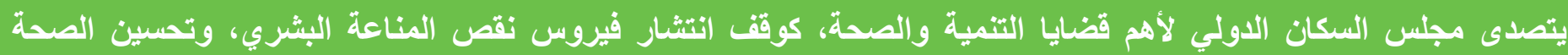

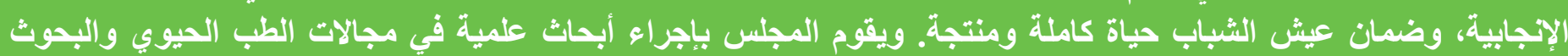

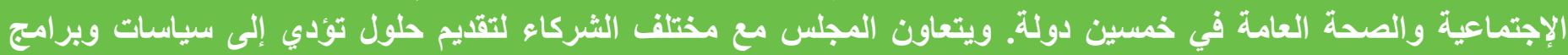

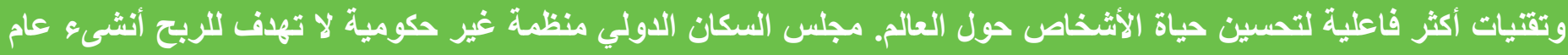

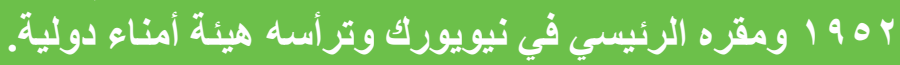

Population Council One Dag Hammarskjold Plaza New York, NY 10017

$$
\begin{aligned}
& \text { هجنس السكان الدولي - مصر } \\
& \text { وه طريق مصر حلو الني الزراعي - المعادي }
\end{aligned}
$$

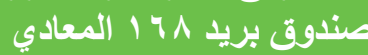

$$
\begin{aligned}
& \text { | القاهرة - مصر برد }
\end{aligned}
$$

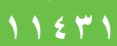

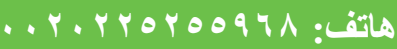

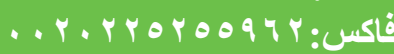

Info.egypt@popcouncil.org:البريد الاكتروني

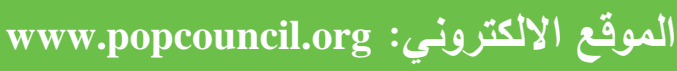

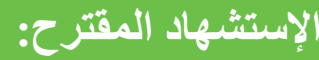

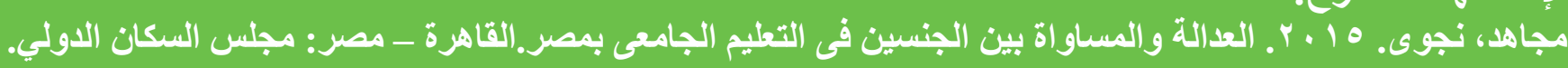

\section{POPULATION COUNCIL}

Ideas. Evidence. Impact. 